\title{
The spectrum of molecules of medium mass as endogenous intoxication indicator in quails with mycotoxicosis
}

\author{
Elena Kuzminova ${ }^{*},{ }^{,}$, Evgeny Dolgov ${ }^{1}$, Marina Semenenko ${ }^{1}$, Denis Osepchuk $^{1}$, and Ksenia \\ Semenenko ${ }^{1}$ \\ ${ }^{1}$ Krasnodar Research Center for Animal Husbandry and Veterinary Medicine, Pervomaiskaya st. 4, \\ Krasnodar, 350055, Russian Federation
}

\begin{abstract}
The paper presents the results of determining the level of molecules of medium mass (MMM) in the blood serum of poultry with experimental mycotoxicosis. The study revealed a relationship between the concentration of MMM in the blood serum and the severity of the pathological process in poultry with different types of mycotoxicosis. The most pronounced changes occur in mycotoxicosis due to the combined intake of T2 toxin and aflatoxin B1 into the poultry body, even when their concentration individually does not exceed the maximum permissible level. In this case, a significant increase in the concentration of MMM in the blood serum is recorded - in 1.8 times $(\lambda=254 \mathrm{~nm})$ and in 2.2 times $(\lambda=280 \mathrm{~nm})$, with an increase in the MMM distribution index. Next, according to the severity of endogenous intoxication, follows mycotoxicosis caused by aflatoxin $\mathrm{B} 1$, and the lowest values were recorded with $\mathrm{T}-2$ toxicosis.
\end{abstract}

\section{Introduction}

Mycotoxins are secondary metabolites of microscopic fungi (molds) that attack feed under favorable conditions for germination - optimal temperature and humidity. According to the UN food organization, at present, up to $30 \%$ of the total world harvest is contaminated with mycotoxins, and in Russia the share of infected feed can reach $80 \%$ of all harvested grain. Considering this, one or more mycotoxins constantly enter the body of animals with feed, which leads to the development of chronic poisoning and secondary immunodeficiency [13].

Currently, there are more than 350 species of microscopic fungi that release at least 300 different mycotoxins into the environment, of which T-2-toxin and aflatoxins are the most dangerous. The main producer of T-2 toxin in Russia is the fungus Fusarium sporotrichioides. The disease is characterized by gastroenteritis, bleeding, stomach ulcers, necrosis of

* Corresponding author: sever291@mail.ru 
the skin and oral mucosa, diarrhea, impaired activity of the central nervous system; abortion and depression of sexual function are possible. The main aflatoxin-producing fungi are toxigenic strains of Aspergillus flavus and Aspergillus parasiticus. Aflatoxin B1 is one of the most dangerous mycotoxins, as it has a pronounced hepatotoxic, mutagenic, carcinogenic and embryotoxic effect [4-5].

It has been proved that with the simultaneous intake of several mycotoxins into the animal's body, they can enhance the toxic effect of each other. So, with the combined effect of $\mathrm{T}-2$ toxin and aflatoxin $\mathrm{B} 1$, their $\mathrm{LD}_{50}$ for white rats is $0.85 \mathrm{mg} / \mathrm{kg}$ and $2.75 \mathrm{mg} / \mathrm{kg}$ body weight, while with separate intake these doses were equal to 2,83 and $8.9 \mathrm{mg} / \mathrm{kg}$ of body weight [6-7].

Taking this into account, the study of aspects of the pathogenesis and methods of diagnostics of mycotoxicoses is an urgent direction in veterinary medicine. At the same time, in spite of a sufficient number of studies devoted to metabolic disorders in mycotoxicosis, in most studies, the revealed metabolic changes are not considered from the standpoint of the accumulation of pathological metabolic products in the body of animals.

It has now been determined that toxic aggression of various origins is accompanied by a nonspecific generalized response of the body in the form of an endogenous intoxication syndrome. Endogenous intoxication is understood as a complex of symptoms of pathological conditions of organs and body systems caused by the accumulation of endotoxins in tissues and biological fluids. Endogenous intoxication accompanies diseases and complications associated with increased tissue breakdown, enhanced catabolic processes, resulting in a violation of microcirculation, with damage to cells and body systems [8-10].

Along with clinical manifestations, endogenous intoxication has biochemical equivalents. As a marker, an indicator of the concentration of medium mass molecules (MMM) is used, which are substances of low and medium molecular weight (500 to $5000 \mathrm{D})$ - mainly fragments of endogenous proteins. The most common detection of two fractions of MMM is at wavelengths of 254 and $280 \mathrm{~nm}$. The fraction of MMM $254 \mathrm{~nm}$ (toxic fraction) is an integral indicator of the content of ultraviolet absorbing substances, which, in addition to proteolysis products, include non-protein substances of normal and abnormal metabolism. The intensity of UV absorption at $280 \mathrm{~nm}$ is mainly determined by the presence of aromatic chromophores, and its increase is due to the accumulation of tyrosine and tryptophancontaining peptides. This may be due to the loss of aromatic amino acids by proteins as a result of oxidative modification and fragmentation of molecules. The most informative is the estimate of the MMM coefficient of $280 / 254 \mathrm{~nm}$, since an increase in this indicator may indicate an increase in catabolic processes, stimulation of lipid peroxidation and immunogenesis [11-15].

The possibilities of the method for determining MMM for identifying intoxication processes in human biological material have very organically fit and are implemented in screening diagnostics of the general condition of the body, and have also become an integral part of identifying the level of deviations in various pathologies. However, data on the concentration of MMM in the body of farm animals, including poultry, are sporadic, which determined the topic of the research.

The objective of the work is to study the content of molecules of medium mass in the blood serum of poultry with experimental mycotoxicosis.

\section{Materials and Methods}

Experimental modeling of mycotoxicosis was carried out on quails of the Texas Pharaoh meat breed at the age of 55 days with a body weight of 310-315 g, divided into 4 groups of 30 heads each. In the experiments, we used poultry that passed the quarantine regime of the Krasnodar Research Veterinary Institute vivarium, which complies with the sanitary rules 
for the design, equipment and maintenance of vivariums. The quails were kept in rooms with a temperature of $22-24{ }^{\circ} \mathrm{C}$, with a relative air humidity of $40-60 \%$, under natural light conditions, in cage batteries. To obtain statistically reliable results, the groups were formed according to the principle of paired analogues.

The technique of reproducing mycotoxicosis consisted in the fact that for 30 days the poultry of the 1st, 2nd and 3rd experimental groups were fed with food naturally contaminated with mycotoxins: in the 1st experimental group with T-2 toxin at a concentration of $0.12 \mathrm{mg} / \mathrm{kg}$ of feed (with the maximum permissible level for poultry (MPL) $-0.1 \mathrm{mg} / \mathrm{kg}$ feed); in the 2nd experimental - with aflatoxin B1 at a concentration of $0.023 \mathrm{mg} / \mathrm{kg}$ of feed (with an MPL of $0.02 \mathrm{mg} / \mathrm{kg}$ of feed); in the 3rd experimental group, a combination of T-2 toxin and aflatoxin B1 was used at concentrations of $0.095 \mathrm{mg} / \mathrm{kg}$ of feed and 0.019 $\mathrm{mg} / \mathrm{kg}$ of feed, respectively (the level of toxins individually did not exceed the MPL, but their combined effect on the body for a long time determines the development of a toxicosis); the 4th group served as an intact control and was kept on a basic high-quality diet. Watering for all poultry was carried out from automatic drinkers, with free access.

The enzyme immunoassay for the content of mycotoxins was carried out on the Stat fax 2600 analyzer using test systems for indirect solid phase competitive enzyme immunoassay of Pharmatech JSC.

All quails were clinically observed, weighing was carried out on the 15th and 30th day of the experiment. At the end of the experimental period, blood was taken from 10 quails from each group, in which the level of endogenous intoxication was determined (by the concentration of MMM). Blood was collected into vacuum tubes with a separating gel and an Apexlab coagulation activator. The concentration of MMM was determined using the screening method of N.I. Gabrielyan, V.I. Lipatov at two wavelengths $\lambda=254 \mathrm{~nm}$ (MMM 254) and $\lambda=280 \mathrm{~nm}$ (MMM 280) [16]. The concentration of MMM was expressed in terms of optical units of a centrifugate obtained after precipitation of plasma proteins with a $10 \%$ solution of trichloroacetic acid. To register the optical density in the ultraviolet region of the spectrum, an Ecoview UV-1100 spectrophotometer was used. The distribution index of MMM was calculated using the formula: DI 280/254 = MMM 280 / MMM 254.

Statistical processing of the obtained results was carried out using the Statistica 10 software. Quantitative characteristics were assessed by comparing the mean values of sample populations with the determination of the Student's $t$ - test, the difference in the arithmetic mean was recognized as statistically significant at $\mathrm{p} \leq 0.05$.

\section{Results}

As a result of the studies, it was found that the first symptoms of intoxication began to appear in quails in the $3 \mathrm{rd}$ experimental group (with toxicosis caused by the combination of T-2 toxin and aflatoxin B1), starting from the 8th day of the experiment. Clinically, a moderate decrease in appetite, depression, decrease in egg production, narrowing of the palpebral fissure, and discharge of serous effusions from the nose and eyes were recorded in the poultry. By the 30th day, poultry of this group showed a significant decrease in appetite, increased thirst, the droppings were of a watery consistency, greenish in color with an admixture of blood, a sharp decrease in egg production was recorded, and in some poultry flowing-out of eggs was noted, while the shell was soft and deformed.

During the period of research, this group recorded the death of 4 quails $(13.3 \%$ of the total). At its pathological autopsy, the depletion of the corpses, dull and disheveled the feather cover, was noted, a significant probing of the keel of the bird was noted. The liver was enlarged in size, full-blooded on the cut, the colour was grey-brown, with multiple areas of hemorrhage in the parenchyma, the gallbladder was full, the contents were bloody with yellowish-green flakes. The thick and small sections of the intestine were increased in 
size, while their wall was depleted, with multiple hemorrhages, full-blooded. When the intestine was cut, an abundant amount of bloody exudate was visualized, multiple hemorrhages on the surface of the mucous membrane. On the pericardium there were areas of hemorrhage, kidney with multiple hemorrhages. The spleen was enlarged, with areas of hemorrhage. In the lungs, a large amount of exudate, the mucous membranes of the upper respiratory tract and air sacs were hyperemic; hemorrhages in the lung tissue were found.

In the 1st experimental group (with toxicosis caused by T-2 toxin), the survival rate of quails over the period of the experiment was $100 \%$, and clinical signs of intoxication (decreased appetite, egg production and weight gain, dullness of the feather cover, while individual feathers did not adhere to each other, but were located relative to the body at different angles, the fan of the feather became loose and lost its elasticity) began to appear from the 20th day of experimental intoxication.

In the 2nd experimental group (with toxicosis caused by aflatoxin B1), the survival rate of quails during the experiment was $93.3 \%$, and the clinical signs of intoxication (depression, decreased appetite, egg production and weight gain, dullness of the feather cover, increased fragility of the shell eggs) began to appear from the 10th day of the experiment. Autopsy of the dead poultry showed an enlarged liver, its blood filling, hemorrhages on the capsule, small punctate hemorrhages were visualized on the mucous membrane, and the intestinal contents were greenish with an admixture of blood.

In poultry of all experimental groups, on the background of the development of mycotoxicosis, negative dynamics of body weight was recorded (Table 1). So, on the 15 th day of research in the 1 st group, the body weight of quails decreased by $6.7 \%$, in the 2 nd group it decreased by $9.2 \%$, in the 3rd group - by $11.4 \%$. On the 30 th day of the experiment, the body weight of quails in relation to the initial data decreased by $8.9 \%$ (1st group) and by $11.5 \%$ (2nd group), with a significant decrease in the body weight of poultry of the 3rd group - by $17.8 \%$. An intact poultry showed an increase in body weight with a difference to the background data by the middle of the experiment - by $6.6 \%$, and by the end - by $12.2 \%$.

Table 1. Dynamics of body weight of quails with experimental mycotoxicosis

$(\mathrm{M} \pm \mathrm{m} ; \mathrm{n}=30)$

\begin{tabular}{|c|c|c|c|}
\hline \multirow{2}{*}{ Groups } & \multicolumn{3}{|c|}{ Body weight, g } \\
\cline { 2 - 4 } & background & $\begin{array}{c}\text { on the 15th day of } \\
\text { the experiment }\end{array}$ & $\begin{array}{c}\text { on the 30th day of } \\
\text { the experiment }\end{array}$ \\
\hline 1 experimental & $313.7 \pm 2.37$ & $292.7 \pm 3.19$ & $285.8 \pm 1.86$ \\
\hline 2 experimental & $315.9 \pm 2.15$ & $286.8 \pm 1.76$ & $279.6 \pm 0.73$ \\
\hline 3 experimental & $312.8 \pm 1.86$ & $277.2 \pm 2.44$ & $257.1 \pm 1.52 *$ \\
\hline 4 control & $314.1 \pm 2.44$ & $336 ., 3 \pm 3.48$ & $358.0 \pm 1.97$ \\
\hline
\end{tabular}

Note: the differences are significant $(* \mathrm{p} \leq 0.05)$ relative to the poultry of the 4 th group

In the course of the studies, it was found that on the background of experimental mycotoxicosis, the levels of MMM in the blood serum of quails in all experimental groups were higher than those of intact control (Table 2).

Table 2. The level of MMM in the blood serum of quails with experimental mycotoxicosis $(\mathrm{M} \pm \mathrm{m}$; $\mathrm{n}=10$ )

\begin{tabular}{|l|c|c|c|c|}
\hline \multirow{2}{*}{ Parameters } & \multicolumn{4}{|c|}{ Groups } \\
\cline { 2 - 5 } & $\begin{array}{c}\mathbf{1} \\
\text { experimental }\end{array}$ & $\begin{array}{c}\mathbf{2} \\
\text { experimental }\end{array}$ & $\begin{array}{c}\mathbf{3} \\
\text { experimental }\end{array}$ & $\begin{array}{c}\mathbf{4} \\
\text { control }\end{array}$ \\
\hline MMM, 254 nm, AU & $0, .653 \pm 0.036$ & $0.714 \pm 0.042$ & $1.019 \pm 0.021^{*}$ & $0.558 \pm 0.034$ \\
\hline MMM, 280 nm, AU & $0.569 \pm 0.029^{*}$ & $0.633 \pm 0.023^{*}$ & $0.921 \pm 0.038^{*}$ & $0.412 \pm 0.025$ \\
\hline DI $280 / 254 \mathrm{~nm}, \mathrm{AU}$ & 0.872 & 0.887 & 0.904 & 0.739 \\
\hline
\end{tabular}

Note: the differences are significant $(* \mathrm{p} \leq 0.05)$ relative to the poultry of the 4 th group 
The maximum increase in both fractions of MMM was observed in the 3rd experimental group with mycotoxicosis caused by the combination of T-2 toxin and aflatoxin B1, and the minimum - in the poultry of the 1st experimental group with experimental T-2 toxicosis. When calculating, the difference relative to the 4th control group was: in the 1st group - by $14.6 \%(\lambda=254 \mathrm{~nm})$ and by $27.6 \%(\lambda=280 \mathrm{~nm})$; in the 2 nd group - by $21.8 \%(\lambda=254 \mathrm{~nm})$ and by $34.9 \%(\lambda=280 \mathrm{~nm})$; in the 3rd group - in 1.8 times $(\lambda=254 \mathrm{~nm})$ and in 2.2 times $(\lambda=280 \mathrm{~nm})$.

To obtain a more complete picture of the development of endogenous intoxication, DI $280 / 254$ was calculated, which in general made it possible to assess the direction of the observed changes in physiological, biochemical and regulatory processes in the direction of pathology or norm and their relationship to each other. Analysis of the distribution index by groups showed that in comparison with the control in the poultry exposed to mycotoxins, this indicator in the 1 st group increased by $15.2 \%$; in the 2 nd group - by $16.6 \%$; in the 3 rd group - by $18.3 \%$.

\section{Conclusion}

Thus, the obtained data indicate that there is a relationship between the concentration of MMM in the blood and the severity of the pathological process in the body of the poultry with mycotoxicosis. The most pronounced changes in the body of poultry occur during mycotoxicosis caused by a combination of T-2 toxin and aflatoxin B1, even when their level individually does not exceed the MPL. In this case, a significant increase in the concentration of MMM in the blood is recorded, with an increase in the index of distribution of MMM. Next, according to the severity of endogenous intoxication, follows myco-toxicosis caused by aflatoxin B1, and the lowest values were recorded with $\mathrm{T}-2$ toxicosis.

Taking into account the results of the conducted studies, the probability that endogenous intoxication plays a very significant role in the development of toxicosis, exacerbating the course of the pathological process, is significant. Since the main feature of MMM lies in their ability to further aggravate metabolic disorders that caused their synthesis, forming a kind of vicious circle $[11,17]$.

In the future, it seems promising to determine the level of MMM in poultry blood serum, since this accessible and highly informative method requires minimal equipment (a spectrophotometer and only one reagent - a $10 \%$ solution of trichloroacetic acid), which, along with conventional laboratory tests, will allow assessing the severity of pathology, the expediency of the treatment, predicting its duration and intensity, as well as dynamically controlling its success in the course of treatment.

The study was supported by the Russian Foundation for Basic Research as part of a scientific project № 19-316-90029.

\section{References}

1. A. Schafer da Silva, J. M. Santurio, L. F. Roza, N. B. Bottari, G. M. Galli, V. M. Morsch, M. R. C. Schetinger, M. D. Baldissera, L. M. Stefani, W. M. Radavelli, T. Tomasi, M. M. Boiago, Microbial Pathogenesis, 107, 309-312 (2017) https://doi.org/10.1016/j.micpath.2017.03.041

2. F. N. Nazar, A. P. Magnoli, A. M. Dalcero, R. H. Marin, Poultry Science, 91(1), 47-54 (2012) https://doi.org/10.3382/ps.2011-01658

3. E. V. Kuzminova, M. P. Semenenko, S. I. Kononenko, A. A. Abramov, E. P. Dolgov, Asian Journal of Pharmaceutics, 12(4), 1236-1241 (2018) http://dx.doi.org/10.22377/ajp.v12i04.2916 
4. M. Buszewska-Forajta, Toxicon, $\quad$ 182, $34-53$ https://doi.org/10.1016/j.toxicon.2020.04.101

5. M. P. Semenenko, E. V. Kuzminova, E. V. Tyapkina, O. A. Fomin, I. A. Rodin, Journal of Environmental Management and Tourism, 7(23), 1334-1339 (2018)

6. R. Salem, N. El-Habashi, S. E. Fadl, O. A. Sakr, Z. I. Elbialy, Environmental Toxicology and Pharmacology, 60, 118-127 (2018) https://doi.org/10.1016/j.etap.2018.04.015

7. R. Jia, Q. Ma, Y. Fan, C. Ji, J. Zhang, T. Liu, L. Zhao, Food and Chemical Toxicology, 90, 142-150 (2016) https://doi.org/10.1016/j.fct.2016.02.010

8. J. He, K. Y. Zhang, D. W. Chen, X. M. Ding, G. D. Feng, X. Ao, Livestock Science, 152(2-3), 200-207 (2013) https://doi.org/10.1016/j.livsci.2012.12.018

9. M. P. Semenenko, E. V. Kuzminova, E. V. Tyapkina, A. A. Abramov, K. A. Semenenko, Journal of Pharmaceutical Sciences and Research (JPSR), 9(9), 1573-1575 (2017)

10. J. K. Akintunde, S. A. Ayeni, M. A. Adeoye, A. O. Shittu, Environmental Toxicology and Pharmacology, 74, 103293 (2020) https://doi.org/10.1016/j.etap.2019.103293

11. H. I. Ahmed, E. Ransom-Jones, S. Sadiq, A. Vitlic, N. McLay, M. F. Rojas, E. C. Ale, A. G. Binetti, A. Collett, P. N. Humphreys, A. P. Laws, Carbohydrate Research, 488, 107909 (2020) https://doi.org/10.1016/j.carres.2020.107909

12. M. N. Naseem, M. K. Saleemi, A. Khan, A. Khatoon, S. T. Gul, F. Rizvi, I. Ahmad, A. Fayyaz, Microbial Pathogenesis, 121, 147-154 (2018) https://doi.org/10.1016/j.micpath.2018.05.021

13. J. E. N. Tilley, J. L. Grimes, M. D. Koci, R. A. Ali, C. R. Stark, P. K. Nighot, T. F. Middleton, A. C. Fahrenholz, Poultry Science, 96(12), 4236-4244 (2017) https://doi.org/10.3382/ps/pex214

14. A. C. Pappas, E. Tsiplakou, M. Georgiadou, C. Anagnostopoulos, A. N. Markoglou, K. Liapis, G. Zervas, Applied Clay Science, 99, 48-53 (2014) https://doi.org/10.1016/j.clay.2014.06.009

15. W. L. Bryden, Animal Feed Science and Technology, 173(1-2), 134-158 (2012) https://doi.org/10.1016/j.anifeedsci.2011.12.014

16. C. F. de Oliveira, C. H. Corassin, B. Correa, I. P. Oswald, Encyclopedia of Agriculture and Food Systems, 358-377 (2014) https://doi.org/10.1016/B978-0-444-525123.00200-X

17. N. Dolai, I. Karmakar, R. B. S. Kumar, B. Kar, A. Bala, P. K. Haldar, Asian Pasific Journal of Tropical Biomedicine, 2(1), 243-251 (2012) https://doi.org/10.1016/S22211691(12)60168-3 